THURSDAY, AUGUST 30, I9oo.

\section{RIGHT- AND LEFT-HANDEDNESS.}

Rechts-undLinkshändigkeit. Von Dr. Fritz Lueddeckens. Pp. vi +82 . (Leipzig: Engelmann, rgoo.)

THE chief interest of the treatise under consideration consists in the exposition of a variety of conditions which, in the author's opinion, are associated with that commonly known as right-handedness, a condition which is generally assumed to refer to a greater physical development and functional employment of that side of the body. Moreover, the author seeks to refer all the phenomena upon which his extended conception of right- (or left-) handedness is based to a common cause, which he finds in the existence of a higher degree of blood-pressure in the vessels of one side of the head (and in the common instance, viz. the right-handed one, in the vessels of the left side) than in those of the other. Dr. Lueddeckens is thus firstly concerned to prove the existence of such an inequality in blood-pressure as has just been mentioned, and the earlier pages of his book are devoted to this part of the subject. From an account of the embryological history of the arterial system, and the departures from original bilateral symmetry which that system presents, we are led (p. 8) to a study of the hydrodynamic conditions obtaining in the aortic arch in the living subject, and in this connection it is argued that the circumstances are such as will produce a higher blood-pressure in the left than in the right common carotid artery. The greater frequencies of cerebral hxemorrhage, and of embolism of the arteria centralis retine on the left side of the brain, are urged in further support of this view.

If it be conceded that the cerebral hemispheres may differ in respect of the pressure in their arterial systems, it becomes possible to divide individuals into three classes, viz. those in whom the blood-pressure is higher on the left side; those in whom the pressure is higher on the right side ; and, finally, there must be a category in which will be ranged such cases as present a degree of bloodpressure which is the same in each hemisphere. The majority of cases will, it is believed, fall within the first of these divisions, and to such cases (ordinary righthanded persons) our attention is first directed: evidence is drawn from a comparison of the structures supplied by the chief branches of the common carotid arteries of each side, and firstly of the structures in the area supplied by the external carotid artery, including various superficial structures and also the ear (internal maxillary artery), and the conclusion is arrived at that there is a predominance in growth and a more easily excitable nervous sensibility (auditory sensations being especially observed) on the left side, such preponderance being directly associated with the higher blood-pressure on that side.

In the second place, a number of observations on the shape of the eyeball, and on the comparative dimensions of the two eyes in the same individual, are discussed.
For it is argued that a difference in blood-pressure will find expression in a difference in the shape of the eyeball on the same side, and that this difference in shape will, in turn, be manifested by differences between the two eyes, in respect of sight. And it is finally submitted that observations on the respective refractive powers in the two eyes of a number of persons examined with regard to this point bear out the conclusion which was thus arrived at on a priori grounds.

Thirdly, differences in the size of the pupil on the two sides are taken as criteria of differences in blood-pressure, the smaller pupil corresponding to the higher blood-pressure, and vice versâ. Thus we should, according to the author's argument, expect normally to observe differences in this respect. But inasmuch as such difference between the pupils is, by many authorities, considered to accompany pathological conditions only, the author is at considerable pains to show that a purely physiological difference in size may exist. And so again, his arguments that the difference in blood-pressure will be manifested by a difference in the pupils, and further that the difference is normally (in right-handed persons, that is) indicative of a higher blood-pressure on the left side of the head, are considered to be justified by the number of cases in which the smaller of two "physiologically" unequal pupils was observed in the left eye.

Turning from the special domain of ophthalmic anatomy and physiology, the relative weights of the cerebral hemispheres next claim attention, and Hamarberg's results are quoted as indicative of a slight excess of weight in favour of the left hemisphere. The conformation of the several cortical areas is then described, in allusion to their well-known connection with the voluntary production of movements (and of speech in particular). Sensory phenomena are next considered, and evidence of a rightsided predominance in nervous excitability is adduced from the results of work by Biervliet (on the muscular sense, taste, hearing, sight); and lastly, psychical events are dealt with, though with much brevity owing to the difficulty of obtaining relevant evidence.

Passing briefly over the category of subjects in whom an equal blood-pressure is presumed to obtain on both sides of the head, the remaining class in which the bloodpressure on the right side of the head exceeds that on the left is dealt with much in the same way, and in nearly as much detail, as the first class; and with very similar results, mutatis mutandis: in other words, Dr. Lueddeckens finds in the majority of left-handed persons the various sources of evidence which have previously been detailed, and which indicate in the left handed persons a higher blood-pressure on the right side of the head, just as they indicated this condition on the left side of the head in right-handed persons. Interesting observations on the psychical phenomena of young left-handed individuals are recorded, and in particular their difficulties in learning to write, their tendency to adopt mirror-writing, and the greater frequency of impediments to speech among the lefthanded may here be noted. Finally, the tendency of the left-handed to lie on the left side during sleep is commented upon.

The foregoing sketch will, it is thought, render the NO. I609 VOL. 62] 
following comments intelligible. Firstly, the demon. stration of an essential and fundamental point, viz. the higher degree of blood-pressure in the area supplied by the left common carotid artery, leaves a good deal in the way of direct evidence to be desired : the most important point urged in support being perhaps the comparatively greater frequency of cerebral hæmorrhage on the left side. The author admits that, as regards the brain, the confluence of the two vertebral arteries (to form the basilar) equalises the conditions on the two sides so far as the parts (medulla, pons, and posterior parts of hemispheres) supplied by these are concerned, whereas the equalising effect is not supposed to be felt in other parts of the circle of Willis. We regret that we can find no direct guidance on this point in Hill's important work on the cerebral circulation.

The arrangement of the great vessels springing from the aortic arch is also a subject that admits of a good deal of discussion in the present connection.

With reference to the auditory nerve (p. I6), and the greater sensibility of the auditory centre in the left hemisphere, it may be mentioned that some support is afforded to this view by the earlier date at which the auditory fibres running up to the first temporal gyrus in the left hemisphere acquire their medulla, and presumably attain a fully functional state (Flechsig). In his observations on the eye, the author is to be congratulated on having devised new applications of routine clinical methods to the elucidation of the questions with which he deals. As regards actual differences in the dimensions of the eyes, it is remarkable that no evidence on this subject is forthcoming from the otherwise exhaustive work by $\mathrm{L}$. Weiss on the anatomy of the eye (Anatomische Hefte, Bd. viii. 1897). The recognition of non-pathological differences in the size of the pupils is a point on which it is worth while to insist; moreover, the phenomenon will lose little, if any, of its importance as a physical sign in the early diagnosis of certain nervous diseases (e.g. general paralysis of the insane). As regards the weights of the hemispheres of the brain, it may be well to remark that there appears to be a mis-quotation on p. 49 , where the weight of a left cerebral hemisphere is stated to be $218 \mathrm{gm}$., and that of the corresponding right hemisphere $133 \mathrm{gm}$. only; at any rate, if there is not a mistake in quoting Hamarberg's figures, the brain could hardly be regarded as other than pathological, and consequently valueless in this connection. But more important than this is the fact that Braune's extensive weighings show that the difference between the two hemispheres is quite negligible. At the same time we may mention that, according to Bastian, the specific gravity of the left hemisphere exceeds that of the right. Finally, we do not feel inclined to agree with the author in explaining instances of the existence of double personalities on the supposed presence of equal blood-pressure in right and left common carotid arteries.

On the whole, we think that while the amount of evidence in support of the author's main assumption might well be increased, at the same time the clear record of observations, and the deliberate discussion of their significance, will render Dr. Lueddeckens' volume of much interest to biologists.

W. L. H. DuCkworTH.
MODERN VIEWS ON THE CHARACTERS OF THE CELLULAR ELEMENTS IN THE BLOOD.

Histology of the Blood: Normal and Pathological. By P. Ehrlich and A. Lazarus. Edited and translated by W. Myers, M.A., M.B., B.Sc. Pp. xiii + 2i6. (Cambridge: At the University Press, I900.)

VOT much more than a year has elapsed since the first part of "die Anæmie," by Ehrlich and Lazarus, appeared in Nothnagel's "System of Pathology and Therapeutics"; but during that short time the work has taken a foremost place among those dealing with the histology of the blood. Perhaps the most striking feature of the book is its originality, broad lines being laid down along which future investigators may work, and no subject is taken up without being enriched by some suggestive hypothesis based on interesting observations made by Ehrlich himself or some of his pupils. Although comparatively a small book, it may be said, without disparagement to the many other works on hæmatology, to be the one to which the term "epoch-making" may, without exaggeration, be applied. It is only possible to refer shortly to some of the most important subjects discussed in its pages. Although it is undoubtedly with reference to the leucccytes that the most important observations are made, there are also points of great interest treated of in the chapter dealing with the morphology of the erythrocytes. This is especially the case with regard to the authors' views on polychromatophilia as a sign of degeneration, and on the method of transformation of megaloblasts to megalocytes and normoblasts to normocytes. Not less important are the paragraphs dealing with the megaloblastic type of the blood and marrow in pernicious anæmia. But it is when the authors come to discuss the normal and pathological histology of the white blood corpuscles that we find on every page observations that shed light on points that have been long in obscurity.

Although the authors belong to a comparatively small school that believes in the absolutely distinct characters of two types of white blood corpuscles, lymphocytes and granular leucocytes, yet no one, whatever his own opinions may be, can rise from a perusal of these pages without granting that no stronger case could have been presented in support of this view than the one placed before us in this book. Perhaps it is mainly to Ehrlich and Ribbert in Germany, and Muir in this country, that we are indebted for the most powerful arguments against the view that all leucocytes are developed from the lymphocyte. The arguments presented in this book in favour of the view that there are two great types of white cells, are obtained from morphological, experimental, pathological and clinical data. The morphological characters of the different forms of white cells are first described in a very lucid manner. There is an exceedingly valuable contribution to our knowledge of the functions of the spleen in Kurloff's work on the effects of removal of that organ from guinea-pigs. The functions of the lymph glands and bone marrow are described, and additional evidence is given in favour of the two-fold type of the white blood corpuscle.

The chapter dealing with the demonstration of the cell granules and their significance is, of course, one in which Ehrlich, as a pioneer in this subject, naturally finds him- 